Wilfrid Laurier University

Scholars Commons @ Laurier

Psychology Faculty Publications

Psychology

Spring 2005

\title{
Moving Forward: Negotiating Self and External Circumstances in Recovery
}

Joanna Ochocka

Centre for Research and Education in Human Services

Geoffrey Nelson

Wilfrid Laurier University, gnelson@wlu.ca

Rich Janzen

Centre for Research and Education in Human Services

Follow this and additional works at: https://scholars.wlu.ca/psyc_faculty

Part of the Psychiatry and Psychology Commons

\section{Recommended Citation}

Ochocka, Joanna; Nelson, Geoffrey; and Janzen, Rich, "Moving Forward: Negotiating Self and External Circumstances in Recovery" (2005). Psychology Faculty Publications. 14.

https://scholars.wlu.ca/psyc_faculty/14

This Article is brought to you for free and open access by the Psychology at Scholars Commons @ Laurier. It has been accepted for inclusion in Psychology Faculty Publications by an authorized administrator of Scholars Commons@Laurier. For more information, please contact scholarscommons@wlu.ca. 


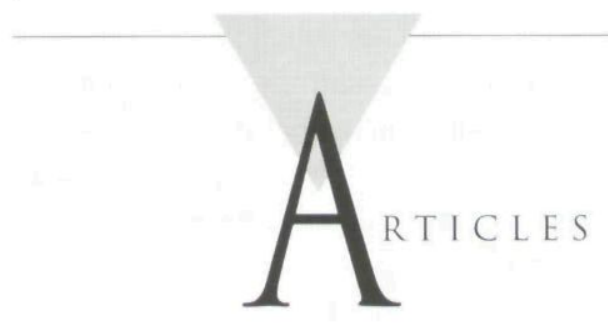

\section{MOVING FORWARD: Negotiating Self and EXTERNAL CIRCUMSTANCES IN RECOVERY}

Joanna Ochocka, Geoff Nelson \& Rich Janzen

JOANNA OCHOCKA, PHD, IS DIRECTOR, CENTRE FOR RESEARCH AND EDUCATION IN Human SERVICES, Ontario, Canada.

Geoff nelson, PhD, is a Professor, DEPARTMENT OF PSYCHOLOGY, WILFRID LAURIER UNIVERSITY.

Rich JANZEN, MA, IS SENIOR RESEARCHER, CENTRE FOR RESEARCH AND EDUCATION IN Human SERVICES, ONTARIO, CANADA.

DIRECT REQUESTS FOR FURTHER INFORMATION ABOUT THIS STUDY TO JOANNA OCHOCKA AT jOanna@crehs.on.ca.

THIS RESEARCH WAS ONE OF SEVERAL PROJECTS FUNDED UNDER THE COMMUNITY MEntal Health EVAluation Initiative (CMHEI) BY THE ONTARIO MINISTRY OF HEALTH AND LONG-TERM CARE THROUGH THE ONTARIO MENTAL HEALTH OUNDATION. WE WOULD LIKE TO THANK STAFF MEMBERS OF THE CENTRE FOR RESEARCH AND EDUCATION IN HUMAN SERVICES, WHO COMPRISED THE RESEARCH TEAM FOR THIS PROJECT AND WHO ASSISTED WITH DATA COLLECTION AND ANALYSIS; MEMBERS OF THE ONTARIO PEER DEVELOPMENT INITIATIVE AND THE FOUR CONSUMER/SURVIVOR INITIATIVES WHO PARTICIPATED ON THE PROJECT STEERING COMMITTEE AND GUIDED THE CONCEPTUALIZATION, IMPLEMENTATION, INTERPRETATION, AND DISSEMINATION OF THE RESEARCH; AND THE INVESTIGATORS FOR THE CMHEI AND RESEARCH STAFF OF THE HEALTH SYSTEMS RESEARCH AND CONSULTING UNIT, CENTRE FOR ADDICTION AND MENTAL HEALTH, TORONTO, FOR THEIR WORK IN COORDINATING ALL OF THE PROJECTS AND FOR PROCESSING ALL OF THE DATA.

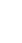

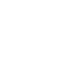

(n)


organizations, Recovery Inc., in 1937

(Low, 1951). Recently recovery has been promoted by William Anthony and other researchers, as well as by people who have experienced serious mental health struggles (Allot \& Loganathan, 2002; Anthony, 1993). The notion of recovery has its seeds in several firstperson accounts. People with serious mental illnesses have shared their experiences of how they overcame symptoms of a diagnosed mental illness and how they found a way to live a satisfying, hopeful, and productive life, even with limitations caused by illness and oppressive external circumstances (Capponi, 2003; Deegan, 1988, 1996).

One recovery theme focuses on the personal changes that people make, which is often constructed in terms of stages of a recovery process. People with significant mental health challenges characterize the period before the beginning of the recovery journey as being one in which they experience despair and feelings of being "stuck" and powerless, and the end of the recovery journey as having achieved an improved quality of life, control, and hope (Baxter \& Diehl, 1998; Young \& Ensing, 1999). Another theme in recovery research is the critical factors involved in this process (Smith, 2000), including "turning points" (Lucksted, 1997).

The context of recovery, including internal and external conditions that influence personal change, is another theme (Jacobson, 2001; Ralph, 2000). The focus is not only on personal change and empowerment but also on the socio-environmental and community context of these changes, including the many socially constructed barriers to recovery (Smith, 2000). For example, Nelson, Lord and Ochocka (2001b) suggest that mental health should be defined broadly by including not only personal changes and empowerment, as most of research focuses on, but community participation and integration, as well as acquisition of basic life resources like housing, income and employment. However, most people with serious mental health problems experience stigma, social exclusion, and poverty because of the oppressive social context in which they live (Nelson, et al., 2001b). Thus, recovery entails not just recovery from mental illness, but also recovery from troubled relationships, discrimination, and social injustice.

One problem with the literature on recovery is that there are inconsistencies in the way key concepts are described. Often different researchers and writers use different words to refer to similar concepts. For example, Jacobson (2001) describes connections/interconnectedness as an internal factor for recovery and an external factor according to Ralph (2000). Furthermore, several recovery studies and conceptual pieces do not link key concepts, showing the inter-relationships between the concepts. Because of these inconsistencies and the lack of linking of key concepts, we believe that concept clarification regarding recovery is needed.

\section{Background of Study}

Our framework for understanding recovery is based on the findings of a longitudinal study of Consumer/ Survivor Initiatives (CSIs) in community mental health in Ontario, Canada. CSIs are self-help/mutual aid organizations that are operated exclusively by and for people with serious mental illnesses. Both quantitative and qualitative approaches were used in this study. The study has been conducted by implementing a participatory action research approach, in which people in recovery and professional researchers have actively collaborated since the inception of the research to develop a re- search approach and process that is valued by all stakeholders (Ochocka, Janzen \& Nelson, 2002). Almost all of the qualitative interviews were conducted by consumer/survivors.

The recovery framework we present in this article is based on the data from the qualitative interviews with 28 study participants (12 active in CSIs and 16 not active in CSIs) at baseline, 9month, and 18-month follow-up interviews. These in-depth, semi-structured interviews typically lasted 1 to 2 hours and covered topics such as what life was like when mental health problems were first experienced, past experiences with services and supports, and personal life changes that occurred in the previous 9 months. The interviews were transcribed and analyzed using content analysis and the qualitative software program, NUDIST. The authors of this article were involved in data analysis and met over a period of 1 year to discuss data interpretations and conclusions. The consumer/survivor researchers also took part in these discussions. This multi-researcher approach to data analysis increased the trustworthiness of the data interpretations. It is important to note that our purpose is to examine key themes in the process of recovery for all participants.

\section{A New Framework for Understanding Recovery}

Based on our findings we developed a new framework for understanding recovery that is illustrated in the diagram below. This framework attempts to synthesize and address some of the inconsistencies noted previously regarding the concept of recovery.

From Figure 1, we see that recovery is a complex and multidimensional process. Our framework emphasizes that the recovery process is ongoing (motivated by a drive to "move for- 


\section{FIGURE 1-“THE DRIVE TO MOVE FORWARD"}

A framework for understanding the negotiation of self and external circumstances by people living with serious mental illnesses and other serious life struggles

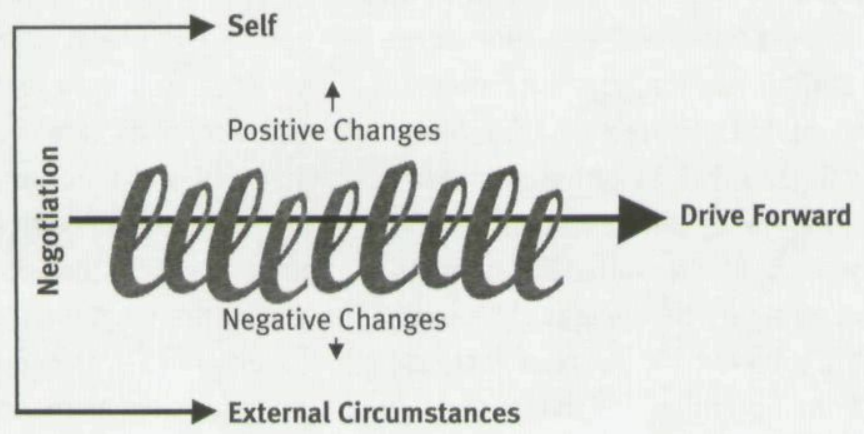

ward"), is non-linear including both successes (positive changes) and setbacks (negative changes), and is ecologically oriented (lived within the context of self and external circumstances). It is a dialectic process in which each individual continually tries to make sense of and respond to the dual realities of what is going on inside of themselves and the external circumstances within which she/he lives (process of negotiation). The outcome of each negotiation can contribute to positive or negative changes, which further add to life experiences and influence the results of future negotiations.

The main components of this recovery framework include the drive to move forward (intrinsic life motivation) and the spiral of life struggle that results in positive and negative changes (life changes). These life changes demonstrate the outcomes of recovery, which are grounded in the context of self and external circumstances (life context). Finally there is the ongoing negotiation between self and external circumstances (mechanisms of life change). We will describe each of these four components in turn.

\section{The Drive to Move Forward: Life Motivation}

The first component of the recovery framework is the middle, forward moving line in Figure 1 . This is what we have labeled as the "drive to move forward." We argue that every human being is involved in his/her own personal growth and life struggle. The drive to move forward, the motivation for survival to live in spite of struggle, is a critical life element among all people.

Everyone has their bad days, or bad weeks, because of stress or just because. But overall, [my life] was moving forward.

People with serious mental health issues have an ongoing struggle to overcome mental health challenges and oppressive life circumstances. In our study many individuals expressed an urge to move ahead in their lives. This drive was a desire to improve their lives and to prepare for their future.

The drive to move forward is an important part of the journey of recovery and is like the growth motivation described by humanistic psychologists (e.g., Maslow, 1954; Rogers, 1961). Sometimes people feel that they are "stuck in a rut," powerless, paralyzed, and in a state of inertia (Deegan, 1988; Lucksted, 1997; Young \& Ensing, 1999). Central to this journey is an underlying intrinsic motivation-a source of power, or internal push that mobilizes strengths, in an effort to realize new life and positive personal change. Some of the components of this theme are as follows.

\section{Hope and Optimism}

Renewed hope and optimism was a driving force toward recovery for a number of participants. Some participants indicated that the hope and optimism were related to the responsibility coming from forming and maintaining relationships. One participant described this with passion:

\footnotetext{
I started to have a hope. I got a positive view. I definitely became more satisfied with my life. And I love a lot of things, but when [new friend] came, there is now ... no limit to love. [...] I have my [sense] of hope and sense of life.
}

\section{Determination}

Other participants talked about the drive to move forward in terms of determination and survival. For some participants a strong will to make things work and not to give up was the most important factor to move their lives forward. An example is:

\section{I realized that I have a strong faith about my life. [...] I just go ahead de- spite my fear. And I know I will go ahead.}

\section{Faith in a Higher Power}

Some participants made a reference to religion or spirituality as a source of moving forward. Looking to a higher power or something outside themselves gave people strength and motivation. A few people spoke in depth of the strength they gain from spiritual involvement in their lives and from connecting with a higher power. 
I think that sometimes I do go into depths of depression, some real dark depths of depression. But what I try to do and I have been successful thus far, is to use [...] the chanting of a religious statement. Believing in God keeps me focused.

\section{Awakening}

Participants talked about getting started on the road to recovery often as awakenings or turning points. The impact of turning points were in their motivation to move forward. They were bursts of energy forward. Turning points help to renew hope and purpose. They can provide the courage to live and to love.

The death of my cousin last January. I went to his funeral and you've got to appreciate every day I think. That got into my thinking. [...]Sounds negative, but I started to have a piece of paper that I write positive stuff down and try to keep every day.

\section{The Spiral of Life Struggle: Positive and Negative Life Changes}

The spiral at the center of the framework represents life changes. Life can be thought of as a series of happenings, a constant struggle between positive times of personal growth and negative times of setback. As people move on in life, they live in a dynamic process of change from which they gain their experiences. Positive life changes are represented by the part of the spiral that turns forward, giving a sense of success and mastery in life. Negative life changes are those times of moving backward, temporary setbacks that move life in a direction that is undesirable. The framework we propose reminds us of the simple truth that recovery is not a linear process marked by successive accomplishments.
Examples we heard about positive life changes included improved relationships in people's lives, increased community involvement, more selfconfidence and assertiveness, more control over one's mental health treatment, more independence, and more self-care. These findings are similar to those reported by Nelson, Lord, and Ochocka (2001a). Negative changes, on the other hand, were associated with setbacks in life. Negative life changes included a general decrease in general health, increased loneliness, increased relationship difficulties, increased financial difficulties, and work-related negative changes.

\section{The Context of Life Struggle: The Self and External Circumstances}

The change process towards recovery is ecologically oriented, lived within the context of the self and external circumstances. In Figure 1, this third component is represented at the top and bottom of the diagram. People live in the context of two main realities: the reality of the self and the reality of external circumstance (Jacobson \& Greenley, 2001). Much has been written about the internal forces in the recovery literature (Jacobson, 2001; Ralph, 2000). Consistent with this literature, study participants also discussed their internal states. Most notably they spoke of their emotions, physical health, psychiatric symptoms, confidence, attitudes, reaction to medication, and sense of power that they feel. Moving forward towards recovery meant gaining a certain mastery over these personal dimensions.

Additionally, the findings of our study highlight external circumstances that impact on the process of recovery. Life's struggles do not happen in a vacuum. There are a number of external circumstances that were mentioned by participants that facilitate or impede life changes. Similar to Fisher (1993), who defined recovery as a human right "to create a positive culture of healing and recovery-oriented services" ( $p$. 22), participants emphasized the importance of social support, responsive services, appropriate housing, work, and income as external circumstances that facilitated recovery. On the other hand, lack of support, stigma, unresponsive or inaccessible services, poor quality housing, unemployment, and poverty hinder recovery. These findings are similar to those reported in previous qualitative research (Nelson, Lord, Ochocka, 2001b; Smith, 2000).

\section{Negotiating Self and External Circumstances: How People Move Forward}

An important way that the proposed framework contributes to the understanding of recovery is the constant negotiation between the self and external circumstances impinging on a person's life. By negotiation we mean the dialectic process by which each individual continually tries to make sense of and respond to the dual realities of what is going on inside of him/herself, and the external circumstances within which he/she lives. The process of negotiation is ongoing and each person plays a central role as an agent or broker. Positive and negative changes are the outcomes of each negotiation. People undertake negotiation as the concrete expression of their desire to move forward toward recovery. Or perhaps more accurately, the drive to move forward propels the active negotiation in each person's life. Such a negotiation can provide a sense of control over life and allows consumer/survivors to overcome and even thrive despite struggles.

The process of negotiation is different for every person and it is often disordered. This element of disorder high- 
lights the fact that a mixture of personal, social and cultural barriers, together with existing relationships, experiences, knowledge and perspectives, combine with living situations to make up the field of negotiation (both self and external circumstances). For many of the participants their internal mental health struggles were at the center of negotiations. There was a dialectic process of not having any hope and then going through steps to regain hope. The example below shows the struggle that one person felt between the wish for and need to work (external circumstance), but the concern and worry about his mental health (self).

I started thinking that maybe I could start back to work. There are still so many things-I would like to go back [to]. What happens if I wake up that morning and I can't go out of the house? That fear. I think that I have to get over those phobias, but how do I get over those phobias when I don't even know what the hell they are?

How does this negotiation work? The process of negotiation is rooted in empowerment theory (Lord \& Hutchison, 1993; Rappaport, 1987; Zimmerman, 2000), which focuses on self-control, determination and participation, and in stress and coping theory (Lazarus, 1991), which focuses on how people cope with life stressors and strains. The person as an active agent of change responds to the need for change by using resources (in thoughts, feelings and actions) to deal with external circumstances, especially those that are stressful and oppressive. Participants talked about negotiations in two different ways, as accommodation-oriented or as action-oriented processes.

Accommodation-oriented negotiations involve the acceptance of the situation, whereas action-oriented negotiations involve change-oriented thinking and action.

\section{Accommodation-Oriented Negotiation Strategies}

Acceptance of limits and capacities. Some participants talked about the process of negotiation starting with their acceptance of the limitations related to their mental health. The clearest example of how the process of negotiation works, and more importantly, how the participants understand this process of negotiation is seen in the way that the participants learned how to set boundaries in their lives. Learning how much is too much in terms of activities, learning one's own limits and capabilities, and being able to clearly express feelings, were some of the examples of negotiations participants discussed. "I do have to be careful and take steps to ensure that I don't take on too great a task."

Knowing one's illness. Knowing limitations related to the specific mental illness helps one to negotiate external circumstances to move forward. Observing and reflecting on one's own health and knowing that "it is okay to be depressed," seem to be important negotiation strategies.

Being realistic in setting goals. For some participants, the negotiation process involved setting realistic goals. It was important to set goals, but goals that are possible to reach. The process of achieving goals was very rewarding.

\section{Balancing various aspects of life. $A$} number of participants expressed the importance of considering different parts of life. Keeping a balance among various parts of life "...whether it be spiritual or financial or your health or your family, work environment" was expressed as a crucial skill when negotiating self in different life situations.

\section{Action-Oriented Negotiation Strategies}

Positive thinking. Some participants described the importance of the way that they view the world around them. Having a positive attitude towards life and other people and reminding oneself to think positively even when times are rough were important for the recovery process. One person said, "I try to think positive and get away from the depressing, the negative."

Taking control. Taking control was an important negotiation strategy. In the study participants discussed the sense of control that they had over their lives in relation to many factors including their mental health, living situations, sense of self, income, and employment situations. Examples include:

\footnotetext{
The power and control, I have more of that because I am on my own and I can do whatever I want to do. How I am going to be treated, my choice of different meds and if I don't agree with them I still have that choice.
}

Taking control of medication and educating oneself about mental health issues were useful negotiation strategies. Many participants expressed the importance of learning about themselves through a better understanding of their condition. "The more I learn about mental health the better I get in mental health."

Seeking support. Outreaching for help and using support systems were useful negotiation strategies. Some participants were able to outreach to the network they already have, others needed to build support from scratch.

Engaging in systems change. A small number of participants talked about acting with others towards systems improvements. Creating awareness of and responding to mental health irrational prejudices and advocating for 
mental health policy change were examples of action-oriented negotiation strategies.

\section{Discussion}

The purpose of this article was to clarify the concept of recovery by presenting a grounded theory analysis of the components of recovery. Through qualitative research with people with serious mental illness, we have identified several key components of the recovery process and suggested how these different components are interrelated. We have called the basic motivational impetus for recovery the drive to move forward, which is the foundation or starting point for recovery. This drive to move forward includes hope, optimism, determination, faith in a higher power, and awakening of motivation. While many of these qualities have been reported in previous research and first-person accounts of recovery (Allot \& Loganathan, 2002; Deegan, 1988, 1996; Ridgway, 2001), we see all of these qualities as characteristic of the broader theme of motivation.

Many people who have experienced a serious mental illness have had this basic motivation for growth squashed or diminished by tormenting symptoms, lost self-confidence, a spoiled identity, troubled relationships, abuse, psychiatric labeling, coercive "treatment," poverty, and other oppressive external circumstances. Feeling "stuck," numbed, powerless, paralyzed, and unmotivated becomes commonplace, when professionallyprescribed treatment regimes emphasize "compliance" rather than selfdirected growth. A recovery-oriented approach to support begins with the premise that the person needs to have a belief in the possibility of personal growth before positive personal changes can occur (Anthony, 1993, 2000; Jacobson \& Curtis, 2000). In the words of Deegan (1988) recovery begins with a "flame of hope and courage" (p. 14). Professionals need to learn to help people rekindle this flame.

A second component of recovery that we identified is the spiral of the life struggle, which involves periods of positive changes and growth and periods of setbacks and discouragement. The spiral of life struggle is not something that is unique to people with serious mental health challenges. Every human being is involved in his/her own personal growth and life struggle. Whoever the person or whatever his/her life stage, there is something common to the experience. Yet the depth of the struggle, and the sense of triumph when overcome, is especially pronounced for people with serious mental illness. We identified a number of both positive and negative life changes in the lives of people with serious mental illness that characterize the highs and lows of the spiral of the life struggle. These changes are quite similar to those reported in previous qualitative research (Nelson et al., 2001a).

The spiral of life struggle reminds us of the simple truth that recovery is not a linear process, as has been emphasized in previous theoretical analyses, research studies, and first-person accounts (Allot \& Loganathan, 2002; Deegan, 1988, 1996; Ridgway, 2001). Recovery is not marked by successive accomplishments, but rather it is a dynamic process of change that is punctuated with periods of relapse, as well as positive growth. Several qualitative studies have conceptualized the recovery process in terms of stages of growth (Baxter \& Diehl, 1998; Young \& Ensing, 1999). We assert that the spiral of the life struggle is a better way of understanding the change process of recovery than a conceptualization in terms of stages. Stages do convey forward movement, but they can also suggest a linear process. The idea of a spiral of change captures both forward movement or growth and the gains and setbacks that occur along the journey of growth.

The third component in our analysis is the context of recovery. One danger in the notion of recovery is an emphasis only on the attributes of individuals. Such a psycho-centric emphasis can reinforce the belief that individuals are responsible for their difficulties, thus blaming the victims for their problems. In their analysis of the concept of empowerment, Rappaport (1987) and Zimmerman (2000) assert that empowerment also has contextual aspects and entails a transactional process between individuals and their environments. Likewise, the concept of recovery does not refer exclusively to personal attributes; it also has contextual aspects, which have a marked influence on the spiral of the life struggle.

While previous research on recovery has proposed two broad dimensions of internal and external factors in the recovery process (Jacobson \& Greenley, 2001; Ralph, 2000), we believe that an ecological analysis of multiple, nested levels provides a more differentiated analysis of the context of recovery (Jacobson, 2001). One can conceptualize the context of recovery in terms of several levels of analysis: the illness, the self, relationships with others, social structures and social systems, and spirituality. In response to the question: recovery from what? a multi-level, contextual analysis illustrates that there is: recovery from serious mental illnesses, recovery of a positive sense of self, restoration of damaged relationships or the development of new, more positive relationships, resistance against oppressive social structures 
and processes and reclaiming of human rights, community, and social justice, and reconnection or connection with a higher power.

Previous research (Smith, 2000) and first-person accounts (Capponi, 2003; Deegan, 1988) have identified the many personal, relational, and systemic barriers and obstacles facing people with serious mental illnesses. The exercise of recovery is personal and political. It is not just illnesses or other life struggles that generate problems, but rather the nature of systems that undermine people's confidence and competence (Lord \& Dufort, 1996; Prilleltensky \& Gonick, 1996; Smith, 1990). What is required is a fundamental transformation of the values and practices not just of the mental health system, but of society as a whole (Deegan, 1988). Transformative values include choice, self-determination, social inclusion, social justice, and spirituality, and transformative practices include Person Centered, Person Directed services, self-help, supported housing, education, employment, and socialization (Deegan, 1988; Smith, 2000). These are contextual dimensions that promote the individual's drive to move forward.

Finally, as others have observed (Deegan, 1996), some of the participants spoke of recovery as a spiritual journey, a connection with a higher power. Finding meaning and purpose is a key part of recovery, and some people search and find this meaning in their spiritual beliefs.

The last recovery component is the negotiation of self and external circumstances. While previous research has identified strategies for recovery (e.g., Smith, 2000), we found two distinct strategies in the negotiation process: accommodation-acceptance and action-resistance. In the coping literature, Lazarus (1991) has made a similar distinction between types of coping strategies. While these two strategies appear on the surface to be quite different, they are, in fact, interrelated. As Deegan (1988) has stated: "This is the paradox of recovery, i.e., that in accepting what we cannot do or be, we begin to discover who we can be and what we can do" (p. 15). Accommodation-oriented strategies appear to be emphasized in self-help organizations like Schizophrenics Anonymous, which utilize a 12-step program, based on the AA approach. Such programs espouse both a medical model of illness and belief in a higher power. While personal agency is invoked in this approach, it is within a larger framework that emphasizes "acceptance of one's illness" as a fundamental premise. In contrast, other self-help organizations are based on the belief that psychiatric survivors are oppressed and that radical social change and survivor empowerment are needed to change the mental system and other social systems. Not surprisingly, such settings emphasize more empowerment and action-oriented negotiation strategies (Lucksted, 1997).

\section{Conclusion}

In this article we have attempted to contribute to the ongoing dialogue about recovery and to clarify the understanding and language regarding this concept by presenting a grounded theory analysis based on a qualitative study of people with serious mental illnesses. We believe that the contribution of this paper to the recovery dialogue is threefold. First, the grounded theory that we have presented depicts the dialectical nature of the process of recovery as a constant negotiation between self and external circumstances. Second, this grounded theory offers insights into the process of positive personal change that, while nonlinear, is motivated by a drive to "move forward." Such a hope-filled drive is fueled as much by personal agency and self-determination, as it is by mystery and grace. Third, the grounded theory presented herein contributes to a portrayal of people dealing with life struggles in a way that is uniquely personal, yet common to that experienced by all people. While the depths of experience may vary greatly (with people with serious mental illnesses experiencing emotional and mental struggles at a deep level), the process of successfully negotiating life's struggles strikes at the heart of what it means to be a human being.

\section{References}

Allot, P., \& Loganathan, L. (2002). Discovering hope for recovery from a British perspective: A review of a sample of recovery literature, implications for practice and systems change. Unpublished paper.

Anthony, W. (1993). Recovery from mental illness: The guiding vision of the mental health service system in the 1990 s. Psychosocial Rehabilitation Journal, 16(4), 11-24.

Anthony, W. (2000). A recovery-oriented service system: Setting some system level standards. Psychiatric Rehabilitation Journal, 24, 159-168.

Baxter, E. A., \& Diehl, S. (1998). Emotional stages: Consumers and family members recovering from the trauma of mental illness. Psychiatric Rehabilitation Journal, 21, 349-355.

Capponi, P. (2003). Beyond the crazy house: Changing the future of madness. Toronto: Penguin.

Deegan, P. (1988). Recovery: The lived experience of rehabilitation. Psychosocial Rehabilitation Journal, 11(4), 11-19.

Deegan, P. (1996). Recovery as a journey of the heart. Psychiatric Rehabilitation Journal, 19, 91-97.

Fisher, D. (1993). Towards a positive culture of healing. In the Massachusetts DMH Core Curriculum.

Jacobson, N. (2001). Experiencing recovery: A dimensional analysis of recovery narratives. Psychiatric Rehabilitation Journal, $24,248-256$. 
Jacobson, N., \& Curtis, L. (2000). Recovery as policy in mental health services: Strategies emerging from the states. Psychiatric Rehabilitation Journal, 23, 333-341.

Jacobson, N. \& Greenley, D., (2001). What is recovery? A conceptual model and explication. Psychiatric Services, 52, 482-485.

Lazarus, R. (1991). Emotion and adaptation. Oxford University Press.

Lord, J., \& Dufort, F. (1996). Introduction: Power and oppression in mental health. Canadian Journal of Community Mental Health, 15(2), 5-11.

Lord, J., \& Hutchison, P. (1993). The process of empowerment: Implications for theory and practice. Canadian Journal of Community Mental Health, 12(1) 5-22.

Low, A. A. (1951). Mental health through will training: A system of self-help in psy. chotherapy as practiced by Recovery, Inc. Boston: Christopher Publishing House.

Lucksted, A. (1997). Turning points and empowerment: Final report of the on our own empowerment interviews. Unpublished report.

Maslow, A. H. (1954). Motivation and personality. New York: Harper and Row.

Nelson, G., Lord, J., \& Ochocka, J. (2001a). Empowerment and mental health in community: Narratives of psychiatric consumer/survivors. Journal of Community \& Applied Social Psychology, 11, 125-142.

Nelson, G., Lord, J., \& Ochocka, J. (2001b). Shifting the paradigm in community mental health: Towards empowerment and community. University of Toronto Press.

Ochocka, J., Janzen, R., \& Nelson, G. (2002). Sharing power and knowledge: Professional and mental health consumer/survivor researchers working together in a participatory action research project. Psychiatric Rehabilitation Journal, 25(4), 379-387.

Prilleltensky, I., \& Gonick, L. (1996). Politics change, oppression remains: On the psychology and politics of oppression. Journal of Political Psychology, 17, 127-148.

Ralph, R. O. (2000). Recovery. Psychiatric Rehabilitation Skills, 4(3), Winter.

Rappaport, J. (1987). Terms of empowerment/exemplars of prevention: Towards a theory for community psychology. American Journal of Community Psychology 15, 121-144.

Ridgway, P. (2001). Restoring psychiatric disability: Learning from first person recovery narratives. Psychiatric Rehabilitation Journal, 24, 335-343.
Rogers, C. R. (1961). On becoming a person. Boston: Houghton Mifflin.

Smith, D. (1990). The conceptual practices of power: A feminist sociology of knowledge. Toronto: University of Toronto Press.

Smith, M. K. (2000). Recovery from a severe psychiatric disability: Findings of a qualitative study. Psychiatric Rehabilitation Journal, 24, 149-158.

Young, S. L. \& Ensing, D. S. (1999). Exploring recovery from the perspective of people with psychiatric disabilities. Psychiatric Rehabilitation Journal, 22, 219-231.

Zimmerman, M. A. (2000). Empowerment theory: Psychological, organizational, and community levels of analysis. In 1 . Rappaport \& E. Seidman (Eds.), Handbook of community psychology (pp. 43-63). Kluwer Academic/Plenum Publishers. 